\title{
WEBTEACHING: SEQUENCING OF SUBJECT MATTER IN RELATION TO PRIOR KNOWLEDGE OF PUPILS
}

\begin{abstract}
Two experiments are discussed in which the sequencing procedure of webteaching is compared with a linear sequence for the presentation of text material.

In the first experiment variations in the level of prior knowledge of pupils were studied for their influence on the sequencing mode of text presentation. Prior knowledge greatly reduced the effect of the size of sequencing procedures.

In the second experiment pupils with a low level of prior knowledge studied a text, following either a websequence or a linear sequence. Webteaching was superior to linear teaching on a number of dependent variables. It is concluded that webteaching is an effective sequencing procedure in those cases where substantial new learning is required.
\end{abstract}

\section{Introduction}

Norman (1973) introduced the notion of webteaching as a promising procedure for the sequencing of subject matter. This procedure takes into account the cognitive organization of knowledge a pupil already possesses, as well as the organization of knowledge in the subject matter. The procedure is based upon "supposition-assertion." This means that new knowledge must be gradually integrated with existing knowledgestructures. According to webteaching: a) concepts from the prior knowledge structure of pupils must be made explicit, anc b) related to new or to-be-learned concepts according to the relations made explicit in a representation of the subject matter structure.

Webteaching presupposes a detailed description of the concepts and relations in the subject matter to be learned and diagnosis of concepts and relations that will be new or unknown to pupils, in order to present subject matter through the gradual connection of known and unknown information.

Norman (1973 and Thorndyke (1978) regard an integrated manner of 
presentation as superior to a linear combination of concepts. Linear sequences present subject matter from simple to complex concepts (Merrill et al., 1980) and these concepts need not be related to prior knowledge of pupils. The processing of information is dependent upon the connections in a chain of concepts (Gregg, 1976). Webteaching, however, relates concepts in different ways, depending upon the partial understanding of pupils and the connection of concepts in the subject matter structure. Although webteaching seems a promising procedure for sequencing subject matter, there have been few empirical studies so far (Tillema, 1982; Rigney, Munro and Crook, 1979). Two experiments were set up to further investigate the sequencing procedure of webteaching. As webteaching is based on prior knowledge of pupils and the subject matter structure, in the first experiment the influence of prior knowledge on sequencing was elaborated through variation in the level of prior knowledge and in the second experiment an external scheme was provided that made explicit the central information in the subject matter to be learned.

\section{THE INFLUENCE OF PRIOR KNOWLEDGE ON SEQUENCING}

According to Ausubel(1964), understanding of information is only possible when the material to be learned is meaningful to the reader. This implies that in the prior knowledge structure of pupils, concepts must be available that can enhance the assimilation of new material (Mayer, 1981). Numerous experiments within the context of a cognitive theory of instruction have recognized prior knowledge as one of the most influential variables for learning (Anderson, 1977; Norman, 1980; Voss and Bisanz, 1981). With the aid of domain-specific prior knowledge, pupils better identify structural information and have a better opportunity to learn specific and new information in an integrated manner (Hayes-Roth, 1978). Prior knowledge not only influences the encoding of new and specific knowledge, but also guides the processing and elaboration of information (Anderson and Pichert, 1978) that can result in prior knowledge dependent learning. Several experiments on the sequencing of information in relation to different degrees of familiarity with the subject matter have shown (Tobias, 1973; Niedermeyer, 1968) that sequencing has no differential effect in the case of high prior knowledge. This could lead to the conclusion that sequencing is not an important variable in instruction (Tennyson, 1973). However this result was obtained with linear sequences where no explicit reference was made to prior knowledge. It could very well be that sequencing of information, and thus the presentation mode of the subject matter, helps the learner who is not already an expert in the subject matter domain (i.e., in the case of moderate or low familiarity or prior knowledge) to find the structural information and learn new concepts and relations in an integrated way. In the case of minimal differences between the prior knowledge structure of pupils and the subject matter to be 
learned structure, pupils could bridge these differences on their own; i.e., on the basis of learner-generated information processing strategies. Instruction-generated information processing strategies, such as sequencing, could have an effect in the case of substantial new learning requirements. Experiment A investigated whether differences in prior knowledge result in differences in learning for a sequence based either on webteaching or a linear presentation of text material.

\section{THE INFLUENCE OF EXTERNAL SCHEMES ON SEQUENCING}

Sequencing is a design procedure to present the subject matter in a structurally integrated way. It could be argued that providing a pupil with an outline of the subject matter before the material is to be presented (e.g., with the aid of an external scheme) is more helpful to him in learning new information. In this respect, sequencing is not so much an important variable as an opportunity for a pupil who has to find his own sequence or path in the material to be learned. An overview of the subject matter structure could provide this aid. However, Wittrock (1981) states that providing external aids for learning does not automatically result in the enhancement of learning. Providing external aids can facilitate the way in which understanding is obtained in the structure of presented information, but it is accomplished through less effort in the processing of information. Understanding of subject matter is not dependent upon external support with the aid of ready-made schemes, but upon the elaboration and level of processing of that information (Craik, 1979). Experiment B investigated whether providing an orienting task, such as an external scheme about the subject matter structure, has an effect on the presentation of information using either webteaching or a linear sequence.

\section{Experiment A}

An experiment was set up to determine the effect of a websequence versus a linear sequence in text material, given the existence of high versus low prior knowledge of pupils about a topic. It is hypothesized that webteaching leads to results superior to those obtained with a linear sequence, and that there is no interaction between webteaching and prior knowledge.

\section{METHOD}

\section{Subjects}

Fifty-nine pupils in the sixth grade of primary school participated in this experiment within their regular classes. It was assured that there were differences in prior knowledge in the topic under study: knowledge about musical instru- 
ments. This was operationalized by selecting pupils who participated in music lessons (optional instruction) and pupils who did not play an instrument or had not followed music lessons. The teachers provided the experimental materials under supervision of the experimenter.

\section{Design}

The experiment consisted of a pretest, treatment and posttest. The pretest consisted of fifteen open-ended questions about the topic of musical instruments, and asked for factual knowledge (e.g., what do you call a person who writes music?). Pupils who were selected for the low knowledge group but had a high score on the pretest (upper quartile) were excluded.

A reading ability test was given $($ CITO 1979$)$ to be used as a covariable. The treatment consisted of studying a text about the categorization of musical instruments. Two versions of the text were constructed - a linear and a web text version. Text versions were equally distributed among the high and low knowledge groups. The posttest consisted of a multiple choice test with twenty questions about concepts presented in the text, and the number of correct answers was scored. No time limit for reading the text was given.

\section{Construction of text versions}

The original text contained 800 words, treating the categorization of musical instruments, and was used as the linear version. A propositional analysis of the text was performed using the method proposed by Kintsch(1974) that selects structurally related concepts, and is graphically represented in Fig. 1.

Twenty concepts were explicitly defined or elaborated in the text. In constructing the web version of the text, the propositional analysis was used to select text parts in which two or more concepts were related or defined. Together with a diagnosis of pupils' knowledge (scalar estimation by the teacher as to which concepts were new or unknown to pupils) a set of rules was constructed which related concepts to each other: basic rule-known and structural concepts

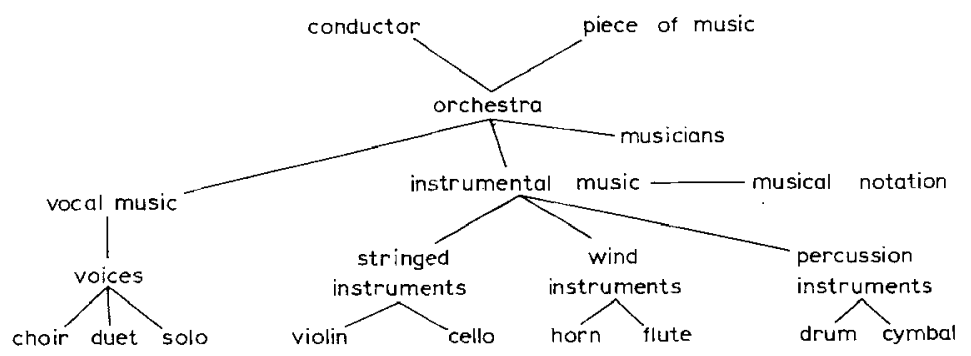

Fig. 1. Network of concepts related to the topic: musical instruments. 
are related; part rules - known concepts and unknown structural concepts are related; connection rules - known and unknown concepts are related.

The web text was established by presenting the original information of the text in the order: basic rule, relevant part rules, and relevant connection rules, etc. The presentation started with known structural concepts such as conductor, orchestra and music in order to introduce related but more specific and unknown concepts, such as wind instruments and flute. The text information in both versions was held constant, only the ordering of text parts (sentences) differed, with minor adjustments in sentence transitions. Pupils were asked to read one of the text versions carefully. No mention was made of later testing.

\section{RESULTS}

The data were analyzed according to a factorial design, consisting of two factors: prior knowledge and the text version, both having two levels with a correction for the influence of the covariable: reading ability. A multivariate covariance analysis was performed. Table I presents the means and standard deviations.

TABLE I

Means and Standard Deviations

\begin{tabular}{lrlrlrl}
\hline Condition & \multicolumn{2}{c}{ Pretest } & \multicolumn{2}{c}{ Posttest } & \multicolumn{2}{c}{ Reading ability } \\
\hline webtext/low prior knowledge & 8.07 & 2.40 & 12.43 & 5.66 & 14.57 & 3.77 \\
webtext/high prior knowledge & 12.63 & 2.47 & 16.75 & 3.71 & 16.13 & 4.17 \\
linear text/low knowledge & 7.46 & 2.66 & 10.92 & 4.94 & 13.92 & 3.56 \\
linear text/high knowledge & 12.81 & 3.46 & 15.06 & 2.99 & 14.81 & 3.31 \\
\hline
\end{tabular}

The first analysis established whether there were significant multivariate mean differences between the factors. The analysis showed no effect for text versions $\left(F_{3,53}=8.83, \mathrm{p}<0.456\right)$; however, prior knowledge contributed significantly (Multivariate $F_{3.53}=16.169, \mathrm{p}<0.0001$ ). Table II gives the univariate

TABLE II

Influence of Prior Knowledge on Dependent Variables

\begin{tabular}{lcl}
\hline Tests & Univariate $F$ & $\mathrm{p}$ \\
\hline pretest & 45.524 & $<0.0001$ \\
posttest & 13.705 & $<0.0005$ \\
reading ability & 1.75 & $<0.1903$ \\
\hline
\end{tabular}


$F$ s. There were no significant interaction effects between prior knowledge and text versions (Multivariate $F_{3,53}=0.365, \mathrm{p}<0.850$ ).

In order to study the influence of prior knowledge further, a multivariate regression analysis was performed to determine the effect on posttest and reading ability test scores. The pretest was used as a predictor of the criterium scores: reading ability and text version differences. Table III gives the results.

\section{TABLE III}

Regression Analysis with one Predictor Variable: Prior Knowledge

\begin{tabular}{lllll}
\hline & Multiple $R^{2}$ & Multiple $R$ & $F$ & $\mathrm{p}$ \\
\hline posttest & 0.362 & 0.606 & 31.33 & $<0.0001$ \\
reading ability & 0.223 & 0.472 & 15.506 & $<0.0003$ \\
\hline
\end{tabular}

It shows that prior knowledge can significantly predict posttest and reading ability test scores. Even if the effect of prior knowledge is partialled out in the analysis, there are no significant differences between the text versions (Multivariate $F_{2,53}=1.31, \mathrm{p}<0.276$ ). If both reading ability and prior knowledge (as learner dependent variables) are used as predictors of posttest scores, they are significant predictors $\left(F_{2,52}=27.83, \mathrm{p}<0.0001\right)$ with a multiple $\left.R^{2}=0.51\right)$. If the influence of both predictor variables is corrected for then the factor text version is still not significant $\left(F_{1,53}=0.051, \mathrm{p}<0.842\right)$.

\section{Experiment B}

A second experiment was set up to compare webteaching with linear sequencing in the case of low prior knowledge of pupils, and to test the effect of externally provided schemes about the subject matter on sequencing.

\section{METHOD}

\section{Subjects}

134 pupils in the highest grade of primary school participated in the experiment. In the selection of pupils it was first assured that they had no regular instruction on the topic: parliamentary democracy. The treatment and testing were administered in their regular classes as part of their usual program. The teacher delivered the materials under the supervision of the experimenter. No mention was made of later testing. 


\section{Design}

The experiment consisted of a pretest, treatment, posttest and retention test. The pretest consisted of a factual knowledge test with twenty questions about the correct description of concepts. The treatment consisted of the random distribution of:

1. A web text version, additionally an external scheme about the subject matter structure $(n=33)$.

2. A web text version (without scheme) $(n=34)$.

3. A linear text version with, additionally, an external scheme $(n=36)$.

4. A linear text version (without scheme) $(n=31)$.

Subjects in the condition with a scheme were instructed to keep the scheme beside the text during reading and check if the information in the text was correctly represented on the scheme. They could study the scheme before, during and after reading. Pupils without the scheme were permitted extra reading time. The total study/reading time for all groups was equal. The posttest consisted of a factual knowledge test (randomly reordered pretest) and a free recall test in which pupils were asked to give a summary of the textual information. This test was taken before the knowledge test in order to avoid cueing. After seven days a retention test was given that consisted of the same tests. Scoring of the free recall test was done by propositional analysis of the summary reports of the pupils which resulted in two scores: a number of concepts score (concepts mentioned in the reports) and a number of relations score (explicitly mentioned relations between two or more concepts). The summary reports were $1-11 / 2$ pages long.

\section{Experimental materials}

The information in the original text ("How our country is ruled" by Van de Veen, 1979) was used as the linear text version. The text consisted of the sequential presentation of concepts with their description, starting with general concepts (democracy, constitution) and progressing to specific concepts (government, elections, party) largely based on argument overlap. In order to construct a web version, a propositional analysis was performed on the text information. Sixteen concepts proved to be central in the information and were rewritten in basic rules, part rules and connection rules. Concepts were scaled with respect to their estimated difficulty by the teachers. The constructed web version presented first a basic rule with its relevant part and connection rules, and progressed to other basic rules until all concepts were covered. The textual information in both versions was the same (concepts and their descriptions).

As a scheme about the subject matter, the graphical representation which resulted from the propositional analysis (a network of concepts) was used.

\section{RESULTS}

The data in this experiment were analyzed as a factorial design with two 


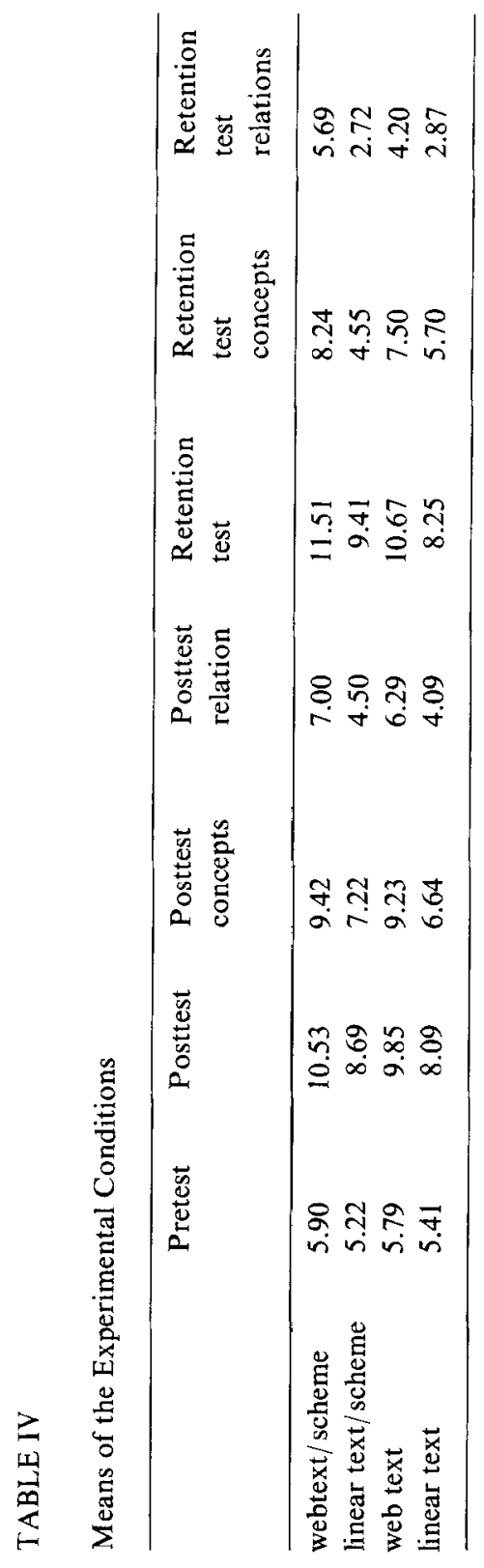


factors: text versions and scheme, both with two levels, tested for several dependent variables (scores) on repeated measurements (pre-, post- and retention test). A multivariate analysis was used. Table IV presents the means of the experimental conditions.

The first analysis investigated whether the two factors of text version and scheme had a differential effect on the knowledge test (both pretest, posttest and retention test). The scheme factor in a multivariate test for differences between mean scores is not significant $\left(F_{3,127}=0.294, \mathrm{p}<0.829\right)$. The treatment factor text sequence, however, is significant on the knowledge test $\left(F_{3,127}=2.90\right.$, $\mathrm{p}<0.037)$. Univariate $F$ s show that webteaching is superior to linear sequencing on both the posttest and the retention test (Table $\mathrm{V})$. There were no interaction effects between sequence and scheme $\left(F_{3,127}=0.352, \mathrm{p}<0.787\right)$.

TABLE V

$F$ Values for the Experimental Condition - Text Sequence

Measured on the Factual Information Test

\begin{tabular}{lll}
\hline Test & Univariate $F$ & $\mathrm{p}$ \\
\hline pretest & 1.127 & $<0.290$ \\
posttest & 6.865 & $<0.009$ \\
retention test & 8.171 & $<0.005$ \\
\hline
\end{tabular}

This analysis was also performed on the free recall test (with two scores: number of concepts and number of relations) both on the posttest and retention measurement. The effect of schemes was not significant (multivariate $F_{4,126}=1.97, \mathrm{p}<0.102$ ). Table VI gives the univariate $F$ s for this condition.

\section{TABLE VI}

$F$ Values for the Experimental Condition - Schemes Measured on the Free Recall Test

\begin{tabular}{lll} 
& Univariate $F$ & $\mathrm{p}$ \\
\hline posttest/concepts & 0.257 & $<0.613$ \\
posttest/relations & 0.141 & $<0.707$ \\
retention test/concepts & 0.525 & $<0.470$ \\
retention test/relations & 0.891 & $<0.347$ \\
\hline
\end{tabular}

Analysis for differences between text versions on the free recall test showed significant differences in favor of the websequence (multivariate $F_{4,126}=6.89$, $\mathrm{p}<0.001$ ). Table VII gives the univariate $F$ and shows that the effect remains on all tests. 
TABLE VII

$F$ Values for the Experimental Condition - Text Sequence Measured on the Free Recall Test

\begin{tabular}{lll}
\hline & Univariate $F$ & $\mathrm{p}$ \\
\hline posttest/concepts & 15.115 & $<0.002$ \\
posttest/relations & 13.694 & $<0.004$ \\
retention test/concepts & 25.53 & $<0.001$ \\
retention test/relations & 22.28 & $<0.001$ \\
\hline
\end{tabular}

This experiment shows that, in the case of low prior knowledge, webteaching leads to higher learning results than linear sequencing of information, providing that external schemes as additional aids to learning do not lead to a differential effect.

\section{Discussion}

Two experiments were performed in order to study the effects of webteaching as a sequencing procedure for the presentation of information in texts to pupils. Webteaching is connected both to the subject matter structure and the knowledge structure a pupil has available. For this reason special attention was given to the influence of prior knowledge and subject matter schemes on the sequencing of information.

The results of the first experiment showed that webteaching does not differ from a linear presentation of textual information, but that prior knowledge is a variable that can predict the differences in results that were found. Inspection of the data revealed that sequencing does not contribute much to the learning of high prior knowledge students, indicating that they could find the structural and central information with the aid of self-generated information processing strategies. However in the case of a low level of prior knowledge, some differences occur between webteaching and linear teaching, although these are not significant.

A second experiment was carried out to investigate the effect of sequencing with a low level of prior knowledge. It was hypothesized that in the case of substantial new learning, the effect of sequencing would help pupils bridge the gap between their own knowledge structure and the knowledge structure to be learned (the subject matter structure). It showed that webteaching was a superior method of sequencing to linear sequencing, both on cued recall (factual knowledge test) and free recall (summary reports). This effect was consistent enough to be repeated on the retention measurement. 
In previous research (Tillema, 1982) with the same learning material, comparable results were obtained. No effects were found for giving an external scheme as an aid for information processing. There are a number of reasons why effective sequencing is important.

In order to understand informative texts in which new or unknown concepts are presented, the reader has to elaborate and integrate central and important information. If a reader is not processing or learning these central concepts, many of the more specific information or concepts introduced later remain meaningless and cannot be integrated in already available knowledge structures. The sequencing of texts offers the reader more and gradual opportunities to bring their available knowledge in accordance with the presented information. Especially in the case of a low level of prior knowledge, text presentation is of importance for the understanding of information.

\section{References}

Anderson, R. C. (1977). "The notion of schemata and the educational enterprise," in R. C. Anderson, J. F. Spiro and W. E. Montague, Schooling and the Acquisition of Knowledge. Hillsdale, N.J.: Erlbaum.

Anderson, R. C. and Pichert, J. W. (1978), "Recall of previously unrecallable information following a shift in perspective," Journal of Verbal Learning and Verbal Behaviour 17: 1-12.

Ausubel, D. P. (1964). "Some psychological aspects of the structure of knowledge," in S. Elam (Ed.), Education and the Structure of Knowledge. Chicago: Rand McNally.

Craik, F. I. G. (1979). "Levels of processing," in L. S. Cermak and F. I. G. Craik (Eds.), Levels of Processing in Human Memory. Hillsdale, N.J.: Erlbaum.

Cito (1979). Toets Basisonderwijs, begrijpend lezen no. 7 (Dutch Reading Ability Test), Arnhem.

Gregg, L. W. (1976). "Methods and models for task analysis in instructional design," in D. Klahr (Ed.), Cognition and Instruction. Hillsdale, N.J.: Erlbaum.

Hayes-Roth, B. (1978). "Structurally integrated versus structurally segregated memory representation," in A. M. Lesgold, J. W. Pellegrino, S. B. Fokkema and R. Glaser (Eds.), Cognition, Psychology and Instruction. New York: Plenum Press.

Kintsch, W. (1974). The Representation of Meaning in Memory. Hillsdale, N.J.: Erlbaum.

Mayer, R. E. (1981). "Instructional variables in text processing." Paper given at International Symposium on Text Processing. Fribourg, September.

Merrill, M. D., Wilson, B. and Kelety, J. G. (1980). "Elaboration theory and cognitive psychology." Paper given at the American Educational Research Association Meeting, Boston.

Niedermeyer, F. C. (1968). "The relevance of frame sequence in programmed instruction," $A . V$. Communication Review 16: 301-317.

Norman, D. A. (1973). “Memory, knowledge and the answering of questions," in R. Solso (Ed.), Contemporary Issues in Cognitive Psychology. Winston.

Norman, D. A. (1980). "What goes on in the mind of the learner," in W. J. McKeachie (Ed.), Learning, Cognition and College Teaching, San Francisco: Jossey-Bass.

Rigney, J. W., Munro, A. and Crook, D. E. (1979). "Teaching task oriented selective reading: a learning strategy," in: H. F. O'Neil and C. B. Spielberger (Eds.) Cognitive and Affective Learning Strategies. New York: Academic Press. 
Tennyson, R. D. (1972). "A review of experimental methodology in instructional task sequencing," A.V. Communication Review 20: 147-159.

Thorndyke, P. W. (1978). "Knowledge transfer in learning from texts," in A. M. Lesgold, J. W. Pellegrino, S. D. Fokkema and R. Glaser (Eds.), Cognitive Psychology and Instruction. (Nato-conference) New York: Plenum.

Tillema, H. (1982). "Sequencing of text material in relation to information processing strategies," British Journal of Educational Psychology 52: 170-178.

Tobias, S. (1973). "Sequence, familiarity and attribute by treatment interactions in programmed instruction," Journal of Educational Psychology 4: 133-141.

Van der Veen, H. J. (1979). Hoe ons Land Geregeerd Wordt ('How our country is ruled'). Zutphen: Thieme.

Voss, J. F. and Bisanz, G. L. (1981). "Models and methods used in the study of prose comprehension and learning." Paper presented at the American Educational Research Association Conference, Los Angeles.

Wittrock, M. C. (1981). "Learning and memory," in F. Farley and L. S. Gordon, Psychology and Education. (The state of the Union.) Berkeley, CA: McCutchan. 